Marquette University

e-Publications@Marquette

Economics Faculty Research and Publications

Economics, Department of

$12-1-2015$

Situating Care in Mainstream Health Economics: An Ethical Dilemma?

John B. Davis

Marquette University, john.davis@marquette.edu

Robert McMaster

University of Glasgow

Accepted version. Journal of Institutional Economics, Vol. 11, No. 4 (December 2015): 749-767. DOI. (C) 2015 Cambridge University Press. Used with permission. 


\title{
Situating care in mainstream health economics: an ethical dilemma?
}

\author{
Forthcoming, Journal of Institutional Economics
}

\author{
JOHN B. DAVIS* \\ Department of Economics, Marquette University, Milwankee, USA, and Faculty of Economics, \\ University of Amsterdam, Amsterdam, Netherlands \\ ROBERT McMASTER** \\ Department of Management, University of Glasgow, Glasgow, UK
}

\begin{abstract}
Standard health economics concentrates on the provision of care by medical professionals. Yet 'care' receives scant analysis; it is portrayed as a spillover effect or externality in the form of interdependent utility functions. In this context care can only be conceived as either acts of altruism or as social capital. Both conceptions are subject to considerable problems stemming from mainstream health economics' reliance on a reductionist social model built around instrumental rationality and consequentialism. Subsequently, this implies a disregard for moral rules and duties and the compassionate aspects of behaviour. Care as an externality is a secondorder concern relative to self-interested utility maximization, and is therefore crowded out by the parameters of the standard model. We outline an alternative relational approach to conceptualising care based on the social embeddedness of the individual that emphasises the ethical properties of care. The deontological dimension of care suggests that standard health economics is likely to undervalue the importance of care and caring in medicine.
\end{abstract}

Keywords: care; health care; health economics; externality; altruism; social capital

JEL codes: I10, A11, D62

*Email: john.davis@mu.edu

** Email: Robert.McMaster@glasgow.ac.uk 


\section{Introduction}

As a field, mainstream or standard health economics applies neoclassical economic reasoning and cost-effectiveness analysis to health care. It explains behavior as constrained utility maximization, and takes a consequentialist approach to the valuation of care (see, for example, Forget 2004; Glied and Smith 2011). Health care is seen as being supplied primarily by medical professionals (Mooney, 2009), and since Arrow's seminal article (1963) the care relationship has been explained in terms of interdependent utility functions and principal-agent relationships between clinicians and patients (McGuire, et al 1982), between "significant others" and patients (Bobinac, et al 2010), between the wider population and those who are ill (Culyer 1976), and in terms of dual utility functions (Wiseman, 1997; Mooney 2009). Distributional issues enter in terms of the idea of merit goods (for example, Tuohy and Glied 2011). The standard approach usually describes merit goods in terms of situations where the maxim of consumer sovereignty is relaxed - consumers are not the best judges of their own welfare and are assumed to usually under-consume such 'goods' as education and some forms of health care, such as inoculations. These commodities may be subsidised because they possess external benefits, which are unlikely to be reflected in their market price. In short, standard health economics privileges the market as an institution: the market is the analytical entry point for health economists. The description of much of health care as a merit good with principal-agent properties invites discussion of market failure and departures from what is taken to be a 'standard' market. In all this, the market retains analytical centrality. Institutional arrangements in the delivery of medical care are seen as primarily correcting for market failure. No reference is made to the history of medicine.

Care is treated as homogenous across those distinctive sets of relationships, although there is some recognition of differences in the intensity of care as a set of practices (Lilly, et al 2010). Within this framework, care can only be conceived as altruism or social capital. In this regard, health economists' understanding of care draws from Gary Becker's (1976) work extending the "economic approach" to the social domain that uses standard analytical tools to re-interpret interactions within the family, addiction, health, and crime in utility maximization terms (for example, Becker 2007; Bobinac, et al 2010; see also, Fine 1999).

We believe, however, that standard health economics offers an inadequate view of care qua care. We argue this is due to its being strictly rooted in the standard utility conception of the individual as a bundle of preferences. This makes the individual a socially dis-embedded being 
(Davis, 2003; 2011; Davis and McMaster 2007), and precludes a more thorough appreciation and understanding of care that recognises its relational, instinctive, socially constructed, and deontological character. To be fair, many health economists recognise the limitations of the standard utilitarian approach to care, though they have also done little to revise it. That is what this paper aims to do.

Care theory is a relatively recent and still contested field having interdisciplinary roots from feminist theory to medicine and education, and as such lacks the cohesion of more established domains of behavioral research. Arguably this is in part due to the amorphous nature of care it is ontologically diverse, ranging from nurturing; to offering or having affection, sympathy, or empathy; to listening; to having an interest; to the discharge of acts and duties associated with a particular role. It is thus at once both natural and socially constructed, frequently gendered, and it is normatively laden. The concept of care has accordingly received rather superficial attention in mainstream health economics, though it was explained in the history of economics in terms of sympathy and altruism by David Hume and Adam Smith, expressed as a key human instinct (the "parental bent") by Thorstein Veblen, and is important in the policy domain as, for instance, articulated in the United Nations' declaration on human rights.

To focus the discussion, we limit the the scope of our analysis to how care is addressed in standard health economics, i.e., in terms of how medical care is provided by medical institutions and professionals, although we stress that our approach, emphasising social embeddedness, encompasses diverse forms of care that transcend disciplinary boundaries. Our aim is to demonstrate the inadequacy of health economics in its 'own territory', and show that its approach cannot readily apprehend the diversity, nuances, and value of care and caring. We emphasise that we do not attempt to establish an alternative approach to the concept of care this is beyond a single paper. Given the growing influence of health economics (Culyer and Newhouse, 2000; Glied and Smith 2011), indeed, especially in the context of the fiscal challenges authorities are endeavouring to address, we feel it is sufficiently appropriate to scrutinise the limitations of its conception of "care".

The remainder of the paper adopts the following structure. In section 2, we discuss health economics' conceptualisation of care as an externality. Section 3 critically evaluates this standard analysis. In section 4 we then analyse the ethical properties of care as set out in the influential work of Tronto (1993, 2013), noting that care's relational dimension implies a socially embedded individual rather than one understood as a bundle of preferences. Section 5 presents our understanding of the relational nature of health-medical care, and more fully 
explains the concept of the socially embedded individual. The final section 6 offers thoughts on the implications for standard health economics' rendering of care.

\section{Mainstream health economics: care as an externality}

Mainstream health economics' entry point for its analysis of care is the delivery of professional medical services to individual patients. Thus, medical care is at one level analogous to the transaction for any good or service, subject to information asymmetries in a patient-physician principal-agent relationship (Mooney and Ryan, 1993). Yet standard health economics acknowledges a potential contradiction between a physician's self-interest via demand inducement (for example, McGuire, 2000; 2011) and acting in ways that promote the patient's welfare (see, for example, Rice, 2001; J Williams, 2012). Indeed, Alan Williams (1988) argued that the patient-physician relation is a "perfect" agency relationship. Then what constrains the physician from inducing demand for their services, or lowering their quality? This tension requires the standard health economics explain care as an externality (see references to this in, for example, Bobinac, et al, 2010; Culyer, 1976; McGuire, et al, 1982), or as an unintended spillover effect of production or consumption not reflected in the price of the activity, i.e. as a market failure. There are two overlappingways in which this has been explained: care as altruism and care as social capital.

\subsection{Care as altruism: interdependent utility functions}

Since Arrow's (1963) article on the economic features of medical care, medical ethics has been acknowledged in standard health economics as means of tempering "consumer exploitation" arising from information asymmetries in the supply of health care. The most prominent interpretation treats medical ethics as both an assurance and insurance against moral hazard associated with behaviour by the agent-physician that is self-interested and misaligned to and damaging to the interests of the principal-patient. It also moderates the potential for adverse selection, which reflects the information asymmetry between buyers (patients) and sellers (physicians) that implies caveat emptor (see Mooney and Ryan, 1993; A. Williams, 1988). McGuire (2000, 521) argues:

"An 'ethic' has the flavor of a dictate or a constraint - once the constraint is binding, other objectives of the physician become irrelevant. Perhaps for this reason, most papers in health economics do not use a constraint to represent ethics, but instead 
represent physician concern for patients with a utility function including as an argument something valued by the patient ... or the patient's utility itself. In this construction, the physician's ethically driven concern for patients is subject to being traded off against self-interest" (emphasis added).

McGuire is explicit that the physician utility function consists of net income accruing to the clinician and the benefits/utility received by the patient. Standard microeconomic accounts of altruism view the benefits accruing to another as an argument in the individual's utility function as a special type of preference having the form: agent X's preference for satisfying agent Y's preferences (Folbre and Goodin, 2004). As Khalil (2003: 116) expresses it, the altruist (qua charity) lowers "his interest in order to buttress the recipient's interest". Yet there is a tension here. Mainstream economics assumes that scarcity is ubiquitous. Famously Arrow (1972) in his critique of Richard Titmuss' (1971) study of altruistic blood donation used the conventional scarcity assumption to argue that a heavy reliance on altruism - or other similar sentiments in the supply of a good or service, would deplete the "resource". Under Arrow's formulation the price mechanism remains the dominant force as it rations scarce commodities and resources efficiently without diminishing altruism. Therefore, altruism, according to Arrow, should be confined to those practices and instances where the price mechanism "breaks down".

The standard framework, in fact, can be seen as distinguishing three approaches to altruism: "egoistic", where altruism revolves around the expectation of future benefits accruing to the benefactor; "egocentric" (which resonates with Becker's approach) where the donor's utility reflects the utility of beneficiaries; and "altercentric" where altruistic actions are associated with a personality trait (Khalil, 2003).

Health economic accounts of "humanitarian spillovers" between the wider population and those who are ill (Culyer, 1976), or care interventions as "spillovers" on "significant others" (Bobanic, et al, 2010) correspond to the Becker-inspired "egocentric" orientation. A "caring externality" in the representative agent's utility function generates a benefit flow to this agent (Mooney and Ryan, 1993) from the knowledge that other members of the population have the ability to access health care regardless of their ability to pay.

A variation on the foregoing is presented by Wiseman (1997), who associates process utility with care in arguing that utility may be derived from the act of caring or giving, as well as the consequences of care-giving. Drawing from Margolis' (1982) fair shares model, Wiseman notes that individuals may be conceived as possessing two utility functions: one deriving from "selfish utility" and the other from group or social activities. In recommending this approach, 
Mooney (2009) invokes Sen's (1977) reference to "commitment" in articulating the idea of a social welfare function "independent" of an individual's utility functions, so that the social welfare function is no longer simply the aggregation of individual utility functions. This dual utility function approach may be viewed as a heuristic device to account for how seemingly irrational acts, seen from a strictly selfish perspective - such as altruistic care giving at personal cost - can be explained as rational acts consistent with utility derived socially. This contrasts with other analyses where the process of care-giving is modelled as burdensome (Bobanic, et $a l, 2010)$.

In effect, two interpretations are offered: care as an argument in the physician utility function and care as a component in a separate "collective" or "social welfare function". Mooney and Wiseman associate the latter with commitment, and say it thereby goes beyond the standard case, which they believe can only accommodate "sympathy" in the form of interdependent functions (Mooney, 2009: 22). Mooney also argues that health economists have "ignored" the contextual element of caring: caring that takes place in a community, which bears some resonance with a process perspective, and thereby identifies a potential distinction between processes and outcomes of care. We agree with Mooney's assessment and commend his emphasis. At the same time, however, we feel the dual utility function approach does not capture all the relevant dimensions of care, as we argue below. Moreover, in the dual utility case it remains theoretically plausible for a meta-function to serve as the appropriate maximand with all the resulting trade-offs (see also Brennan's 1993 critique). Further, the dual function approach does not depart from the standard frame in its exclusive reliance on consequentialist reasoning. Care is a form of other-regarding behaviour, but limitedly so. As the quotation from McGuire above makes explicit, arguments (or utility functions) in the individual's (meta) utility function may be traded off against one another.

\subsection{Care as social capital}

The health economics literature consistently refers to health care as a "special commodity" (see for example, Becker, 2007; Culyer and Newhouse, 2000; Jones, et al, 2006, and McGuire, et al, 1982, see also, Mooney's, 2009, advocacy of a "community" health care commodity). Indeed, in echoes of Culyer's (1976) "humanitarian spillovers" idea, Tuohy and Glied (2011) discuss the distribution of health care in terms of its status as a merit good. Governments then intervene to ensure certain levels of minimum health care for those on lower incomes by constraining the health care choices of those on higher incomes through the redistribution of resources. Tuohy and Glied's analysis and others like it do not explicitly attempt to analyse 
conceptions of care; instead they are focused on the distribution of (medical) care resources (see also J Williams', 2012, study of geographical variations in medical care utilization).

Treating care as an externality makes it as an aspect of social capital, since most contributions to this approach define social capital in terms of non-rivalrous public goods (Folland, 2006) or overtly as an externality (Portes, 1998). The social capital literature supposes that caring social relationships have powerful beneficial effects on health. A considerable literature also recognizes the potential for the indirect effects of social capital on health through its associations with politico-economic and environmental variables that influence health, such as access to resources (for example, Dahl and Malmberg-Heimonen, 2010).

Although they do not refer explicitly to social capital, Bobinac et al's (2010) model of informal care is informative in that it seeks to expand health economics beyond its principal focus on the physician-as-carer by using the standard externality account. Those close to an ill individual benefit from improvements to this individual's health status by virtue of their relationship to that individual - "the significant other(s)". In contrast, Bobinac et al's "caregiver effect" refers to the welfare effects of providing care as a set of activities. Their hypothesis reflects the standard assumption of the disutility of work in that the greater the caregiving activities involved the greater the adverse impact of the care provider's welfare, through for instance, emotional stress and opportunity costs in time commitment. The authors claim the two effects are difficult to disentangle as informal care tends to be provided by a common unit - the family.

Bobinac et al also argue that the family effect of informal care offers an important insight: care provision has welfare effects beyond the care provider-recipient relationship, and therefore that their research ultimately shows: "patients should not be seen as isolated individuals" (Bobinac et al, 2010: 555). Again, such claims have some correspondence to Culyer's "humanitarian spillovers", and they also represent the social dimension of care in interdependent utility function terms. We agree with Bobinac et al's advocacy: the patient should not be viewed as an isolated individual. Indeed, their allusion to the social hints at relations nested in further relations, and thus departs from the standard view of social capital as a "plausible" economic concept when it is reformulated at the individual level (Folland, 2006). Nonetheless, Bobanic, et al and Folland share their analytical grounding in Becker's individualist model of altruism within the family.

\section{Problems: an inadequate treatment of care?}


Care, we believe, has not been explained adequately in the mainstream health economics framework, because the interaction between the individual patient and clinician has been framed as one solely between individuals who are instrumentally rational utility maximizers. This is also the case in those models that seek to account for welfare beyond the physicianpatient relation (for example, Bobinac, et al, 2010; Burge, et al, 2010; Lilly, et al, 2010).

We do not deny that individuals in many walks of life are instrumentally rational. We do deny that this form of behaviour fully describes patient-clinician relationships. We also believe that restricting the analysis and policy thinking regarding health care institutions to populations of instrumentally rational utility maximizers can produce institutional accommodations that are inimical to improving patients' health. For example, the instrumental rationality framing of care encourages clinics and hospitals to measure care as a set of well-defined, standardized procedures that produce determinate outcomes, while crowding out the less tangible and less measurable therapeutic, compassionate, and deontological dimensions of care Our general view is that how health care is provided to people fundamentally depends on how health care institutions are designed, and we believe they can be designed to emphasize the aspects of care neglected in standard health economics.

\subsection{Care as altruism}

The orthodox economic analysis of altruism has been heavily criticised, and by extension much of this criticism may be applied to health economics' view of care as altruism. In Khalil's (2003) egocentric account of altruism, altruists favour health care on account of its expected benefits to them. However, Khalil argues, altruism thus understood has a paradoxical quality in that it can be equivalent to masochism as the altruist gains more the more wretched the state of the parties receiving care. This is logically consistent with Culyer's idea of "humanitarian spillover" and the interdependence of clinician-patient utility functions. Nonetheless, it seems hardly humanitarian or caring in a positive sense that others' misery sustains a vicarious sort of utility for the altruistic/caring agent. More specifically, in extremis, under this conception medical cures are the last thing physicians want: therapeutic treatments are ruled out, and medical procedures are reduced to some form of intermittent palliative episodes of "care" followed by periods of tolerating the patient's worsening medical condition (a source of disutility), to be followed by the patient's improvement as a consequence of further episodes of palliative "care" (a source of utility), and so on. Thus, a process of infinite regress is entered as Khalil's masochist mutates into a sadomasochist with a stethoscope. Obviously Arrow's "medical ethics" constrains a physician's toleration of a patient's deteriorating condition, but 
it is only a constraint: the logic of the mainstream conception of vicarious utility implies the physician is motivated to behave in the manner outlined above.

Moreover, the idea of a 'caring externality' is problematic in itself in that the spillover is not on a third-party, as in the standard case, but actually on one of the parties to the exchange, namely, the patient. If we say then, that care providers gain utility when their patients gain utility, does their care for those individuals constitute something over and above the health care services being delivered? Caring externalities might then be thought to counterbalance the negative effects of moral hazard in that the incentives that asymmetric information creates for physicians to pursue individual gain, such as supplier-induced demand, or the sadomasochist case, above, could be offset by the special regard for the well-being of the patient that comes from this caring preference.

However, this will not work, since on the standard view caring defined as an externality still acts as a secondary, non-essential type of factor since health care is delivered whether or not physicians exhibit caring preferences. In contrast, physicians are clearly incentivized to induce patient demand. Thus there should generally be a tendency for caring attitudes, such as compassion, and hence related activities, such as therapeutic care, to be crowded out, or at least become peripheral. Ethical motives, as it were, are always at risk when economic ones dominate. This conclusion is reinforced by the standard view in microeconomics that externalities are only addressed through the intervention of government in the market system. In the case of clinician caring preferences, this implies that unless government or some other institutional authority (medical associations, codes of ethics, etc.) weighs in on the side of patients, one should expect caring preferences to be continually under pressure to be crowded out of medical care markets.

The view of care as altruism is subject to a further problem: how does the altruist know what another agent's preferences are, especially assuming the standard view that preferences are understood to be revealed preferences? Drawing from Bourdieu (1977), Dewey (1922) and Veblen (1994 [1899]), altruism, we suggest, is more appropriately seen as a disposition, in effect a habit, in that it is more suitably conceptualised as a cause of an individual's actions and practices than a consequence. Habit, moreover, can be either dynamically reinforced or weakened through changes in institutional patterns of social interaction.

As Folbre and Goodin (2004 19) argue, the standard account gives: 
"No sense of the way in which professional roles (such as those of a doctor or nurse or teacher) are practised and perfected ... if we were to think purely in terms of specific freestanding preferences and episodic choices emanating from them: we need to think instead in terms of the training and honing of underlying dispositions to act in ways consonant with those roles ...".

This contrasts markedly to Arrow's (1972) scarcity of altruism analysis. If the supply of altruism is limited, as Arrow argues, then there is a case for economizing on it. However, as Singer (1973) argued in his critique of Arrow, such a position conflates altruism and other similar virtues and dispositions to those properties associated with conventional economic goods. This, as Sandel $(2012,128)$ maintains,

"Ignores the possibility that our capacity for love and benevolence is not depleted with use but enlarged with practice".

What we take from this is that treating "care" as a preference in an agent's utility function makes the level of care something determined through an algorithm of utility maximisation. But this framing makes care a highly mechanical affair, and imposes an instrumentalist interpretation on the concept of care. This in turn suggests the body might be understood as a machine, and that ethical values, particularly non-consequentialist deontological ones, have no place in the analysis of care. Following the philosopher Bernard Williams (1985), we say that instrumentalism removes care from the realm of ethical consideration. For Williams, the outcomes of actions certainly warrant classification as ethical considerations, but so to do obligations and duties, as do character dispositions (virtues), given that they affect how individuals deliberate in undertaking or avoiding actions of certain types. Williams' arguments stress deontological value and the social embeddedness of the individual. In contrast, a health economics based on socially dis-embedded individuals imparts, at best, a thin notion of care. Yet it is well recognised in various literatures that therapeutic care, for example, can provide beneficial health outcomes (Adams and Nelson, 2009; Armstrong et al, 2008; Kontos and Naglie, 2009; Watson and Smith, 2002).

\subsection{Care as social capital}

As noted, health economists consider health care a "special" type of commodity - one exhibiting external benefits. We believe there are sufficient grounds for saying that health economists do not appreciate the implications of this narrative. Commodities are things that 
are tradable, therefore monetizable, produced for sale in a market, and therefore where property rights may be identified and transferred (Fine 2001; McMaster 2013). Culyer (1990) is one of the few health economists to seriously reflect on this conceptualisation of health care. $\mathrm{He}$ describes commodities as:

"Goods and services in the everyday sense, whose demand and supply, and whose growth, have been the focus of economists' attention, and whose personal distribution has been the traditional focus of all social scientists having an interest in distributive justice" (1990: 10).

This is appealing, but Culyer goes on to compare the "characteristics" of health care; timeliness, clinical efficacy, and readmission rates, with those of a steak; juiciness, tenderness, and flavour. The implication is that care is solely instrumental in producing its special characteristics, and that the social relations and institutional arrangements involved in health care provision are essentially the same as those governing commodity exchanges, including those involving principal-agent relations. In the extreme, this would seem to suggest that the nature of dependency, as typified by the principal-agent relationship, is reducible to one of the distribution of information between two parties. Regrettably, Culyer's allusion betrays a reductionism that cannot acknowledge let alone analyse the relational qualities of care.

By contrast, much of the care literature emphasises that care and caring are interactive, and hence possess profoundly relational characteristics (Engster, 2005; Mol, 2006; Tronto, 2013). In an economics context Himmelweit (2007: 585) expresses an important implication of the relational dimension of care in a compelling manner:

"Caring because it is the development of a relationship, is manifestly an activity ... in which the output is the care itself ... This means that it is hard to raise the productivity of caring".

In articulating this, Himmelweit draws on Baumol and Bowen's (1965) analysis of the economics of the arts. They argue that productivity rises more quickly in areas of the economy which benefit directly from innovation, investment and/or technological enhancements. However, the arts, according to Baumol and Bowen, cannot benefit from these effects. They use the example of a string quartet - reducing the number of players or demanding that the musicians play more quickly, inter alia, may raise productivity in terms of the number of pieces performed per musician over a given period of time, but would substantially alter the nature of 
the piece. The problem arises from the attempted objectification of the arts. The same can be said about the nature of care.

In the context of nursing and gender, Adams and Nelson (2009) similarly note that many desirable activities focused on therapeutic care are necessarily time costly and attempts to impose codified, standardised procedures are likely to diminish important aspects of caring, such as in the development of relations that potentially elicit more effective diagnoses (see also, Armstrong, et al, 2008; Groopman, 2007; van Staveren, 2001). This is consistent with Kontis and Naglie's (2009) argument that caring does not develop through theoretical learning, and involves experience (tacit knowledge) and "embodied selfhood", i.e. a synthesis of primordial and social being. In short, medical, and other forms of care cannot be captured adequately by appealing to the characteristics of a steak.

\section{Towards a richer conceptualisation of care}

Care, as we have noted, possesses an amorphous quality - it is ontologically diverse: it is at once natural (Churchland 2011) and socially constructed and thusnormatively laden (Baier 1982; Engster 2005). Given this, as Tronto (2013) recognises, care has many meanings - it can denote a burden, it expresses a disposition or action, and is relational, although this is not restricted to human interactions, it extends to objects, 'things'. Indeed, we feel that this is the overriding consensus that emerges from the disparate roots of care theorising - from feminist theory to medicine and nursing, education, philosophy, and sociology, for instance (Baier, 1982; Blustein, 1991; Churchland 2011; Engster 2005; Folbre 1995; Folbre and Nelson 2000; Mol 2006; Noddings 2003; Tronto 1993, 2013; van Staveren 2001, 2005; Watson 2008). For us, in order to capture care, the sociality and hence social embeddedness of individuals has to be acknowledged. This has profound implications for standard health economics, which we outline in the following sections.

An influential definition of care comes from Fisher and Tronto (1990):

"On the most general level, we suggest that caring be viewed as a species activity that includes everything that we do to maintain, continue, and repair our 'world' so that we can live in it as well as possible. That world includes our bodies, or selves, and our environment, all of which we seek to interweave in a complex, life-sustaining web" (cited in Tronto 1993 103; 2013 19, original emphasis). 
Within this "complex web" of care there is an evocation of power, vulnerability and dependence, which carries implications for individual autonomy and capabilities, and the practices of care within institutional settings. Tronto (2013) has defended the level of generality of her definition of the grounds that it is an attempt to provide an over-arching frame from which the manifestations of care and caring may be aligned with particular ethical properties. Thus, the breadth of her definition informs and shapes Tronto's emphasis on care as a series of purposeful activities, which may be further deconstructed as follows.

Tronto (2013) identifies five specific phases of care: care-about - there is some recognition of a need for care; caring-for - where responsibility for addressing these needs is established; care-giving - is the delivery of the caring activities; care-receiving - following the delivery of the care activity there is some response from the entity in receipt of care. Following this, a judgement has to be made as to the extent to which care needs have been addressed. The fifth phase is caring with, which Tronto argues refers to the alignment of caring needs and how they are addressed with democratic commitments to justice, equality and freedom.

These phases of care may be fraught with conflict, given that the need for care is likely to outweigh the ability to deliver care (Engster, 2005; Smith, 1998; Tronto, 2013). For instance, it is well recognised that care may be contingent in that there is a strong inclination for care-for and care-giving to those in closest proximity. Churchland (2011), for example, considers this in terms of the neurobiology of animals (particularly mammals) suggesting that self-care is part of a survival instinct, which also reaches near kin as an extension of the self. Again, Churchland's analysis indicates the significance of the relational aspect of caring. Smith (1998) notes the tensions between spatiality and human similarity in caring. Smith historically situates the issue of spatial differentiation in caring intensity, noting that interdependence and ease of communication are very recent phenomena in human history. Prior to this the prevalence of small-scale societies restricted the treatment of strangers to certain short-term "codes of hospitality" (Smith, 1998 17). Thus, a lack of familiarity can impede the translation of benevolence, as the desire to do good, into beneficence, as doing good. Similarly, Tronto's phases of care may breakdown between care-about and care-giving, by, for instance, the absence of establishing caring-for.

The phases of care may be aligned with particular (overlapping) moral qualities, or virtues (Engster 2005; Tronto 1993, 2013; see also Mol 2006; Noddings 2003). The first phase of care - caring-about - requires the virtue of attentiveness. This implies some sensitivity to situations where caring needs may arise, and therefore demonstrates some degree of empathy (Engster 
2005) and perhaps benevolence - the desire to do good (Smith 1998). Without attentiveness it is unlikely that care-giving, if it occurs, will be effective in addressing caring needs. Attentiveness may be apprehended as a moral obligation by virtue of a social role that entails certain responsibilities. Thus, under Tronto's phases of care, caring-for specifically embodies responsibilities for addressing recognised care needs. In other words, there is an obligation. For Tronto this further suggests an additional moral quality - competence in the delivery or administration of caring actions. She argues: "To be competent to care, given one's caring responsibilities, is not simply a technical issue, but a moral one" (Tronto 2013, 35).

A further virtue is responsiveness, which implies a dialogue between care-provider and receiver to identify the nature of caring needs and whether they have been addressed. Noddings (2003), in particular, emphasises this in terms of sympathy. She refers to the Western aid programme following a devastating earthquake in Afghanistan in the 1990s in which food and clothing were donated, but building materials were required, yet not donated, as a clear example of a lack of responsiveness (and sympathy) and hence, at best, superficial care. Indeed, Blustein's (1991) allusion to the pivotal role of commitment in care further resonates. Commitment framed in terms of a disposition or dedication to something or someone implies responsiveness. However, if a commitment is superficial or perfunctory then dispositions may not be readily translated into particular caring actions.

The literature further refers to respect as a virtue of caring. For Engster (2005) this revolves around the notion that others are worthy of recognition, attention, and responsiveness. In the case of humans respect infers that others should not be treated in a way that is degrading, and should acknowledge their abilities by virtue of their humanity. In other words, an individual's dignity should be ensured. The emphasis is similar to Smith's argument noted earlier, and further corresponds to Entwistle and Watt's (2013) advocacy of capabilities in health care. In this regard, the authors articulate a case for a person-centred (or "person-al" as they term it) approach to delivering medical care founded on the principles of respect and compassion, responsiveness to patients' subjective experiences, and support for capabilities for (patient) autonomy. We believe in fact that an increasing number of health economists and physicians have begun to think in terms of capabilities and person-centered care in connection with their attention to patient-centered outcomes in clinical practice.

From our perspective, the foregoing suggests an overarching caring virtue may be embodied by compassion. In medical care compassion is seen as a traditional attribute conveyed by the Hippocratic ethos (for example, Aasland 2001; Armstrong et al 2008; Groopman 2007; Pellegrino 2006). Compassion is viewed both as a disposition or appreciation of the condition 
of others, and of actively alleviating their adverse condition. Indeed, the Latin etymology is "co-suffering". On this understanding compassion in health care not only embraces attentiveness and responsibility, but also active treatment (or giving of care) - the physician comprehends the suffering of the patient (Cassell 1985). Of course, there are perennial concerns that medical professionals do not always or consistently demonstrate compassion in the discharge of their duties. Aasland (2001), for instance, expresses concern about the (institutional) crowding out of compassion in contemporary medical practice, and Groopman (2007) conveys similar disquiet on the basis of physicians' frequent lack of responsiveness to patients. This further reveals the incongruities of care. For instance, Folbre (1995) refers to the scenario of an ill-humoured nurse providing better, or more appropriate medical care than a loving parent. Following Noddings (2003) such a scenario suggests an absence of caring due to the lack of sympathy expressed - the nurse has not given care in a caring way. Indeed, this seems to question framing care in instrumental (and consequentialist) terms, and reiterates that actions of themselves warrant ethical consideration (B Williams 1985).

Moreover, the foregoing also relates to distinctions between altruism and compassion. As noted, an important element of the standard health economic conceptualisation of care is consistent with altruism. Altruism, like compassion is other-regarding. However, altruism is individualistic in that it does not invoke a moral obligation associated with a particular social role - there is no sense of duty or responsibility. Accordingly, there may be an ephemeral property to altruism that may be subject to instrumental calculations, as in Arrow's (1972) critique of Titmuss and Khalil's (2003) analysis, and therefore less socially embedded than compassion.

Given the foregoing, care then is associated with compassion, drawing from the virtues of caring noted. However, as care is also, to some extent socially constructed in that it is conceived and developed in particular institutions, such as Western medical education. There are obligations, responsibilities, and duties to care arising from an individual's social position. Care need not be altruistic or necessarily imbued in altruistic acts. Thus, care does not only refer to series of functional practices or acts, but is imbued with ethical qualities; this is particularly the case in medical care (Sulmasy 1993; Pellegrino 2006). For Engster (2005), the responsibilities and obligations of caring, in general, are to be founded on our common dependency - at various times in our lives we will be dependent on others for our well-being, and therefore when in a position to be able to offer care we are obligated to do so. In medical care there is an obvious duty on clinical professionals to offer care on the basis of their social position. 


\section{The relational nature of health-medical care and the socially embedded individual}

The medical literature is replete with references to the relational dimension of care (for example, Aasland, 2001; Entwistle and Watt, 2013; Groopman, 2007; Pellegrino 2006; Sulmasy, 1993; Watson and Smith, 2002). Given this, we believe that patients and clinicians should be regarded as socially embedded individuals where this reflects their membership in patient social groups (family and community) and clinician social groups (professional associations), which are jointly responsible for individuals' care. These two social groups are in turn nested in various other social relationships and interact with other social groups indirectly connected to the patient-clinician relationship. Social groups are defined as collections of individuals with shared characteristics that specify membership in those groups, which creates sets of rights and responsibilities that are supported by individuals' collective intentions (Davis, 2003; 2011). By contrast, institutions may be viewed as durable systems of embedded and established social rules that structure social interactions around groups, and which are manifest in enabling and constraining behaviour, and in partly constituting the individual (Hodgson, 2008). Finally, health care systems are taken to be networks of institutions built up around the interaction between these social groups involved in patientclinician relationships.

Thus, our framework explains the provisioning of care socially through how many individuals as members of many social groups interact both directly and indirectly in the social provision of care. Markets indeed operate for health care, but do so in community and national networks structured around social groups. Central to this view is the idea that care thus understood is not between instrumentally rational atomistic individuals linked through (clinician) externalities, but between socially linked individuals for whom it is rational to act on shared goals.

One way in which this social interaction between individuals can be understood is in terms of their expression of shared, or 'we' intentions both within groups and between groups. Shared intentions provide the basis for reciprocal obligations, as when clinicians and patients commit to courses of treatment as a package of care to which they have agreed. These mutual obligations are rational in virtue of individuals freely binding themselves by them when in interaction they come to the point of expressing shared intentions as the outcome of their deliberation over the course of care (Davis and McMaster, 2007; Entwistle and Watt, 2013, see also Mol, 2006). Thus, their rational character does not derive from the particular ends they promote - a consequentialist view - but from the individuals' shared commitment regarding care $-\mathrm{a}$ deontological view. In effect, the constraints which shared intentions produce are 
'internal' to the clinician-patient relationship, rather than 'external' to the two atomistic individuals' interdependent utility functions in the standard analysis. In this way, a personcentred caring regime, where the individual matters, seems to us to be promoted by this type of approach.

The simple difference between first person singular, or 'I' intentions, and first person plural, or 'we' intentions individually expressed points to fundamental differences in individual behaviour. With the former, atomistic individuals express intentions that apply only to themselves and their choices are instrumental to maximizing individual utility - there is no social or impersonal referent. With the latter, individuals express intentions that apply to themselves via the relations they have to others (see also, Entwistle and Watt, 2013, and their references to "person-al capabilities"). Care relationships between patients and clinicians are thus socially embedding, because patients and clinicians share intentions which they implicitly or explicitly represent in 'we' language. This is even the case in circumstances where a patient is incapable of decision-making, such as in comatose or related conditions, as then individuals from the patient's social group (family or friends) stand in on behalf of the patient in virtue of their shared intentions. Thus, pace Wiseman and Mooney, a more appropriate model for explaining care is, in our view, based on a deontological rather than an instrumental rationality. Care has important unconditional, non-instrumental qualities. ${ }^{1}$

\section{Conclusion: implications for standard health economics and its representation of care}

Our examination of the standard health economics approach to conceptualising and modelling care and caring relations reveals, we feel, several important issues, which suggest that further scrutiny of care, health and economics is entirely appropriate, especially in an era when health economics is being actively pursued to inform rationing and resource allocation decisions. Our intention has been to investigate and establish how care is conceived in the standard approach and to identify underlying ethical issues. Mainstream health economics in conceiving care as an externality where economic actors' utilities are interdependent presents, as we have attempted to argue, a rather reductionist analysis: care is either altruism, or a "special commodity" redolent of social capital. That neither is entirely well specified in the little literature that attempts to develop this perhaps further emphasises the peripheral nature of care and caring in the standard account. Moreover, the vulnerability of care to crowding-out from within the parameters of the model suggests an inadequate conceptualisation. Indeed, not only is this inadequate it also implies that the framework is incapable of furnishing one. 
The reductionist and consequentialist characteristics of health economics also present a particular ethical architecture. Care cannot be valued in its own right, only for the measurable results it produces. For us, this infers an overly instrumental and functionalist approach, where care activities are reduced to a series of mechanical tasks that relegate individual circumstances. As has been argued previously, health economics effectively crowds out the patient as an individual (Davis and McMaster 2007). Care and caring as obligations cannot be accommodated by the standard approach. Culyer (1990), unwittingly perhaps, gives the game away when he contrasts the characteristics of care in medicine as analogous to those of a steak.

Indeed, the reductionist tenor of the standard health economics approach points to a chronic undervaluation of care and caring. Accordingly, policy informed by this approach is likely to concentrate resources on measurable standardised procedures and outcomes, which shapes institutional arrangements, such as medical education that may reinforce and reproduce such an undervaluation. Caring about (health) care then becomes peripheral. The standard health economics framing of care divorces it from its deontological dimension, and thereby weakens the rationale for medicine as a normative endeavour. Indeed, we are left with the unfortunate conclusion that mainstream health economics cannot furnish an account for the appearance of care - only its disappearance.

\section{References}

Aasland, O. G. (2001) 'The physician role in transition: is Hippocrates sick? (Introduction)', Social Science and Medicine, 52: 171-173.

Adams, V. and Nelson, J. A. (2009) 'The economics of nursing: articulating care', Feminist Economics, 15: 3-29.

Armstrong, P., Armstrong, H., and Scott-Dixon, K. (2008) Critical to care: The invisible women in health services, Toronto: University of Toronto Press.

Arrow, K. J. (1963) 'Uncertainty and the welfare economics of medical care,' American Economic Review, 53: 941-973.

Arrow, K. J. (1972) 'Gifts and exchanges', Philosophy and Public Affairs, 1: 343-362.

Baumol, W. G. and Bowen, W. G. (1965) 'On the performing arts: the anatomy of their economic problems', American Economic Review, 50: 495-502.

Baier, A. (1982) 'Caring about caring: a reply to Frankfurt', Synthese, 53: 273-290.

Becker, G. S. (1976) The economic approach to human behavior, University of Chicago Press: Chicago. 
Becker, G. S. (2007) 'Health as human capital: synthesis and extensions', Oxford Economic Papers, 59: 379-410.

Blustein, J. (1991) Care and commitment: Taking the personal point of view, Oxford: Oxford University Press.

Bobinac, A., Job, N., van Exel, A., Rutten, F. F. H. and Werner, B. F. (2010) 'Caring for and caring about: disentangling the caregiver effect and the family effect', Journal of Health Economics, 29: 549-556.

Bourdieu, P. (1977) Outline of a theory of practice, Cambridge: Cambridge University Press.

Brennan, T. J. (1993) 'The futility of multiple utility”, Economics and Philosophy, 9: 155-164.

Burge, P., Netten, A. and Gallo, F. (2010) 'Estimating the value of social care', Journal of Health Economics, 29: 883-894.

Cassell, E. (1985) The nature of suffering, Oxford: Oxford University Press.

Churchland, P. S. (2011) Braintrust: what neuroscience tells us about morality, Princeton University Press: Princeton.

Cramer, J. A. (2011) 'Doctors diagnose and prescribe patients decide what to do (Editorial)', Medical Care, 49: 425-426.

Culyer, A. J. (1976) Need and the National Service, Oxford: Martin Robertson.

Culyer, A. J. (1990) 'Commodities, characteristics of commodities, characteristics of people, utilities and the quality of life', in S. Baldwin, C. Godfer, C. \& C. Propper (eds.), Quality of life: perspectives and policy, London: Routledge.

Culyer, A. J. (2006) 'The nature of the commodity 'health care' and its efficient allocation', in A. J. Culyer (ed.), Health economics: critical perspectives on the world economy, London: Routledge.

Culyer, A. J. and Newhouse, J. P. (2000) 'Introduction', in A. J. Culyer, \& J. P. Newhouse, (eds.), The handbook of health economics, Vol. 1A, Amsterdam: North-Holland.

Dahl, E. and Malmberg-Heimonen, I. (2010) 'Social inequality and health: The role of social capital', Sociology of Health \& Illness, 32: 1102-1119.

Davis, J. B. (2003) The theory of the individual in economics: Identity and value, London and New York: Routledge.

Davis, J. B. (2011) Individuals and identity in economics, Cambridge: Cambridge University Press.

Davis, J. B. \& McMaster, R. (2007) 'The individual in mainstream health economics: A case of persona non-grata', Health Care Analysis, 15: 195-210.

Dewey, J. (1922) Human nature and conduct: An introduction to social psychology, New York: Henry Holt.

Engster, D. (2005) 'Rethinking care theory: the practice of caring and the obligation to care', Hypatia, 20: 50-74. 
Entwistle, V. A. and Watt, I. S. (2013) 'Treating patients as persons: using a capabilities approach to support delivery of person-centred care', American Journal of Bioethics, 13: 29-39.

Fine, B. (1999) 'A question of economics: Is it colonizing the social sciences?' Economy and Society, 28: 403-425.

Fine, B. (2001) Social capital versus social theory: Political economy and social science at the turn of the millennium, London: Routledge.

Folbre, N. (1995) 'Holding hands at midnight: the paradox of caring labor', Feminist Economics, 1: 73-92.

Folbre, N. \& Nelson, J. A. (2000) 'For love or money - or both?' Journal of Economic Perspectives, 14: 123-140.

Folbre, N. \& Goodin, R. E. (2004) 'Revealing altruism', Review of Social Economy, 62: 1-25.

Folland, S. (2006) 'Value of life and behavior toward health risks: an interpretation of social capital', Health Economics, 15: 159-171.

Forget, E. L. (2004) 'Contested histories of an applied field: the case of health economics', History of Political Economy, 36: 617-637.

Glied, S. and Smith, P. C. (eds.) (2011) The Oxford handbook of health economics, Oxford: Oxford University Press.

Groopman, J. (2007) How doctors think, Boston: Houghton Mifflin Company.

Grossman, M. (2000) 'The human capital model', in A. J. Culyer, \& J. P. Newhouse (eds.) The handbook of health economics, Amsterdam: North-Holland.

Heritage, J. \& Maynard, D. W. (2006) Problems and prospects in the study of physician-patient interaction: 30 years of research, Annual Review of Sociology, 32: 351-74.

Himmelweit, S. (2007) 'The prospects for caring: economic theory and policy analysis', Cambridge Journal of Economics, 31: 581-599.

Hodgson, G. M. (2008) 'An institutional and evolutionary perspective on health economics', Cambridge Journal of Economics, 32: 235-256.

Jones, A. M., Rice, N. \& Contoyannis, P. (2006) 'The dynamics of health', in A. M. Jones (ed.) Elgar companion to health economics, Cheltenham: Edward Elgar.

Karnieli-Miller, O. \& Eisikovits, Z. (2009) 'Physician as partner or salesman? Shared decisionmaking in real time encounters', Social Science \& Medicine, 69: 1-8.

Khalil, E. L. (2003) 'What is altruism?’ Journal of Economic Psychology, 25: 97-123.

Kontos, P. C. \& Nalie, G. (2009) 'Tacit knowledge of caring and embodied selfhood', Sociology of Health \& Illness, 31: 688-704.

McGuire, A., Henderson, J. and Mooney, G. (1982) The economics of health care: An introductory text, London: Routldege and Kegan Paul. 
McGuire, T. G. (2000) 'Physician agency', in A. J. Culyer, \& J. P. Newhouse, (eds.) The handbook of health economics, Vol. 1A, Amsterdam: North-Holland.

McGuire, T. G. (2011) 'Physician agency and payment for primary medical care', in S. Glied \& P. C. Smith (eds.) The Oxford handbook of health economics, Oxford: Oxford University Press.

McMaster, R. (2013) 'Mainstream health economics and dignity: the commodity narrative as a debilitating solecism?' American Journal of Economics and Sociology, 72: 1-31.

Margolis, H. (1982) Selfishness, altruism and rationality, Cambridge: Cambridge University Press

Mol, A. (2006) The logic of care: Health and the problem of patient choice, London: Routledge.

Mooney, G. (2009) Challenging health economics, Oxford: Oxford University Press.

Mooney, G. and Ryan, M. (1993) 'Agency in health care: getting beyond first principles', Journal of Health Economics, 12: 125-135.

Nelson, J. A. (1999) 'Of markets and martyrs: is it OK to pay well for care?' Feminist Economics, 5: 43-59.

Noddings, N. (2003) Caring: a feminine approach to ethics and moral education, $2^{\text {nd }}$ edition, Berkley: University of California.

Pellegrino, E. D. (2006) 'Toward a reconstruction of medical morality', American Journal of Bioethics, 6: 65-71.

Portes, A. (1998) 'Social capital: its origins and applications in modern sociology', Annиal Review of Sociology, 24: 1-24.

Sandel, M. J. (2012) What money can't buy: the moral limits of markets, New York: Penguin.

Sen, A. (1977) 'Rational fools', Philosophy and Public Affairs, 6: 317-344.

Singer, P. (1973) 'Altruism and commerce: a defense of Titmuss against Arrow', Philosophy and Public Affairs, 2: 312-320.

Smith, D. M. (1998) 'How far should we care? On the spatial scope of beneficence', Progress in Human Geography, 22: 15-38.

Sulmasy, D. P. (1993) 'What's so special about medicine?' Theoretical Medicine, 14: 27-42.

Titmuss, R. M. (1971) The gift relationship: from human blood to social policy, London: George, Allen, and Unwin.

Tronto, J. C. (1993) Moral boundaries: a political argument for an ethic of care, London: Routledge.

Tronto, J. C. (2013) Caring democracy: markets, equality, and justice, New York: New York University Press.

Tuohy, C. H. and Glied, S. (2011) 'The political economy of health care', in S. Glied \& P. C. Smith (eds.) The Oxford handbook of health economics, Oxford: Oxford University Press. 
van Staveren, I. (2001) The values of economics: an Aristotelian approach, London: Routledge. van Staveren, I. (2005) 'Modelling care', Review of Social Economy, 63: 567-586.

Veblen, T. B. (1994 [1899]) The Theory of the Leisure Class, New York: Penguin.

Watson, J. and Smith, M. C. (2002) 'Caring science and the science of unitary human beings: a trans-theoretical discourse for nursing knowledge development', Journal of Advanced Nursing, 37: 452-461.

Williams, A. (1988) 'Priority setting in public and private health care, a guide through the methodological jungle', Journal of Health Economics, 7: 173-183.

Williams, B. (1985) Ethics and the limits of philosophy, London: Fontana.

Williams, J. (2012) 'Geographic variations in health care utilization: effects of social capital and self-interest, and implications for US Medicare policy', Socio-Economic Review, 10: $317-342$.

Wiseman, V. (1997) 'Caring: the neglected health outcome? Or input?' Health Policy, 39: 4353.

\section{Notes}

\footnotetext{
1 The distribution of power in medical relationships has been the subject of extensive discussion (see for example, Heritage and Maynard, 2006; Karnieli-Miller and Eisikovits, 2009; Groopman, 2007). We also recognise shared intentions do not always pertain - patients may defy physician advice, refuse treatment, and even where intentions are shared outcomes may diverge from intent due to errors and practices (see for example, Cramer, 2011). Given space limitations, we leave aside issues of power.
} 